Presented at the Third International Meeting on Electrochromics in London, England, September 8, 1998 and accepted for publication in Electrochimica Acta.

\title{
Effect of Hydrogen Insertion on the Optical Properties of PD-Coated Magnesium Lanthanides
}

\author{
K. von Rottkay, M. Rubin, F. Michalak, R. Armitage, \\ T. Richardson, J. Slack, *P.A. Duine \\ Windows and Daylighting Group \\ Building Technologies Department \\ Environmental Energy Technologies Division \\ Ernest Orlando Lawrence Berkeley National Laboratory \\ University of California \\ Berkeley, CA 94720 \\ *Philips Research Laboratories \\ Prof. Holstlaan 4 \\ 5656 AA Eindhoven \\ The Netherlands
}

September 1998

This work was supported by the Assistant Secretary for Energy Efficiency and Renewable Energy, Office of Building Technology, State and Community Programs, Office of Building Systems of the U.S. Department of Energy under Contract No. DE-AC03-76SF00098. 


\title{
Effect of Hydrogen Insertion on the Optical Properties of PD-Coated Magnesium Lanthanides
}

\author{
K. von Rottkay, M. Rubin, F. Michalak, R. Armitage, T. Richardson, J. Slack \\ E.O. Lawrence Berkeley National Laboratory, Berkeley CA 94720, USA \\ P.A. Duine \\ Philips Research Laboratories, 5656 AA Eindhoven, The Netherlands
}

\begin{abstract}
Metallic magnesium lanthanide thin films upon insertion of hydrogen transform to a highly transparent hydride phase. With a Pd overlayer, the transformation can be produced either by electrochemical insertion of hydrogen or by exposing the film to hydrogen gas. Unlike amorphous oxide electrochromics, the transformation is accompanied by a large change in visible reflectance (about 50\%). The optical switching effect in these materials is investigated in terms of changes in the complex refractive index as determined by variable-angle spectroscopic ellipsometric and normal-incidence radiometric measurements over the solar spectrum. Furthermore the optical effect of converting the Pd cap-layer to $\mathrm{Pd}-\mathrm{H}$ was determined. It is shown that the Pd layer limits the visible transmittance of the hydrided stack to about $35-40 \%$. Whereas the extinction coefficient of the dehydrided LnMg-layers at $550 \mathrm{~nm}$ is between 2.2 and 3.1, it is as low as $10^{-4}$ in the transparent state.
\end{abstract}

\section{Introduction}

A new class of materials in this field has recently been discovered by Huiberts et. al. [1], who showed that yttrium and lanthanum thin films capped with a Pd layer can be reversibly loaded with hydrogen. At hydrogen gas pressures above about $10^{5} \mathrm{~Pa}$ the materials form the trihydride phase $\left(\mathrm{LnH}_{3}\right)$ which is semi-conducting and transparent. At lower hydrogen pressure (e.g., in air) the materials form the dihydride phase $\left(\mathrm{LnH}_{2}\right)$, which is metallic and opaque. Based on this metalto-semiconductor transition a simple gasochromic and electrochromic [2] switchable mirror can be constructed. Even better optical performance can be obtained using magnesium lanthanide alloys [3]. These materials also form a semiconducting hydride at $10^{5} \mathrm{~Pa}$ hydrogen gas pressure. They are color-neutral and show virtually no absorption in the visible. Thin films of magnesium lanthanide alloys transform to a metallic state when exposed to air. Contrary to the lanthanidedihydrides, they show high reflectivity and very low transmission $[3,4]$.

\section{Experimental}

\subsection{Thin film deposition}

Thin films of Gd and GdMg were sputter-deposited on glass substrates coated with transparent conducting tin oxide $\left(\mathrm{SnO}_{2}: \mathrm{F}\right)$ or ITO $\left(\mathrm{In}_{2} \mathrm{O}_{3}: \mathrm{Sn}\right)$. The substrates were washed with isopropanol, dried at $110^{\circ} \mathrm{C}$ and $10^{-4}$ Torr, and Ar plasma-etched for 1-2 minutes at $50 \mathrm{~W}$ before deposition. When substrates were not cleaned sufficiently and/or the current density was too high, the films tended to delaminate from the substrates. This is attributed to stresses built up within the layers 
due to volume increases during hydrogen uptake. Thorough cleaning and plasma etching improved adhesion and eliminated delamination. Base pressures ranged from $2 \times 10-7$ to $5 \times 10^{-7}$ Torr, while the films were sputtered with $1.0 \times 10^{-2}$ Torr Ar. The power density was between 7.9 and $9.8 \mathrm{Wcm}^{-2}$. Samples with film thickness of 100-200 nm were deposited at rates of 18-20 $\mathrm{nm} / \mathrm{min}$. Although the sputtering target was an alloy of composition $\mathrm{Gd}_{0.3} \mathrm{Mg}_{0.7}$ (verified by $\mathrm{x}-$ ray diffraction), the $\mathrm{Gd}_{\mathrm{x}} \mathrm{Mg}_{1-\mathrm{x}}$ film composition was found by Rutherford backscattering to be ca. $\mathrm{Gd}_{0.5} \mathrm{Mg}_{0.5}$. Pure Gd films were also prepared from a $\mathrm{Gd}$ target. Each $\mathrm{Gd}$ or $\mathrm{Gd}_{0.5} \mathrm{Mg}_{0.5}$ film was coated with a 5-20 nm Pd layer. The Pd sputtering conditions were $1.0 \times 10^{-2}$ Torr Ar at $13.6 \mathrm{~W}$ $\left(2.7 \mathrm{~W} . \mathrm{cm}^{-2}\right)$. The Pd layer deposition rate was $0.25 \mathrm{~nm} / \mathrm{s}$. Additional magnesium lanthanide thin films, typically $270 \mathrm{~nm}$ thick, were deposited on fused silica and glass substrates in a HV deposition facility (base pressure $10^{-6} \mathrm{~Pa}$ ) by co-deposition from two electron-beam-guns. The films were capped with an optically thin $(10 \mathrm{~nm}) \mathrm{Pd}$ film.

\subsection{Optical characterization}

Variable-angle spectroscopic ellipsometry (VASE) data were obtained from $280 \mathrm{~nm}$ to $1700 \mathrm{~nm}$ using a rotating analyzer instrument (J.A. Woollam Co.). It measures the ratio of the complex Fresnel reflection coefficients for polarizations parallel ('p') and perpendicular ('s') to the plane of incidence in terms of the ellipsometric values $\Psi$ and $\Delta$, where:

$$
\frac{\tilde{r}_{p}}{\tilde{r}_{s}}=\tan (\Psi) \cdot \exp (i \Delta)
$$

Ellipsometric measurements were taken at three angles to obtain adequate sensitivity over the full spectra range. Near-normal incidence spectra from $250 \mathrm{~nm}$ to $2000 \mathrm{~nm}$ were also recorded using Perkin-Elmer Lambda 19 spectrophotometer. A Lorentz oscillator model was used to represent the dispersion for Pd and the LnMg alloys in order to guarantee the Kramers-Kronig consistency of spectral optical indices. Ellipsometric and radiometric data were fitted together weighting both data types according to their standard deviations. The numerical iteration was performed utilizing a Levenberg-Marquardt algorithm [5]. Infrared reflectance was measured using a Nicolet 5PC FTIR from 4800 to $400 \mathrm{~cm}^{-1}$.

In order to measure optical properties in the transparent hydrided state special sample holders had to be designed: Ellipsometry on the hydrided films was performed from the backside through the substrate. The rare earth hydride with the Pd layer faced a black surfaced aluminum block with an o-ring gasket. Hydrogen gas was passed through the cell by means of two small holes drilled in the aluminum block. This very simple construction proved to yield perfectly repeatable optical data in transparent and reflective states. Backside reflections from the aluminum block did not have to be considered, since the $1 \mathrm{~mm}$ thick O-ring shifted the reflection from the aluminum versus the reflection from the $\mathrm{LnMg} / \mathrm{Pd}$ layer by $3.8 \mathrm{~mm}$ at the minimum angle of incidence of $59^{\circ}$. A $2 \mathrm{~mm}$ narrow detector iris diameter was sufficient to suppress the signal from the aluminum. A similar sample holder was constructed for transmittance measurements. Here a quartz window was inserted in the aluminum block. To eliminate the influence of the sample holder an identical device was placed in the reference beam of the double beam spectrophotometer. Thickness measurements on the LnMg-layer by ellipsometry were only 
possible in the hydrided transparent state. In the reflective dihydride state thickness was measured by surface profilometry (Dektak II).

\subsection{Electrochemical characterization}

The electrochemical tests were carried out in fused silica cells mounted in an optical bench allowing for the measure of the visible transmittance. The electrolyte (5M sodium hydroxide) was kept under a constant nitrogen gas flow. The counter electrode was a platinum foil. Another platinum foil was used as a pseudo-reference electrode. The cells were connected to an Arbin battery test system.

\section{Results}

\subsection{Gas phase switching}

In order to analyze the magnesium lanthanide hydrides under a Pd coating, first Pd thin film optical constants had to be determined, which below $50 \mathrm{~nm}$ thickness proved to be somewhat different from bulk literature data [6-9]. It was assumed that the optical properties of $\mathrm{Pd}$ on $\mathrm{LnMg}$ resemble that of Pd on ITO. The complex refractive index of the ITO substrate had been measured previously [10]. The optical properties of Pd undergo a less dramatic, but nevertheless significant, change under the influence of hydrogen (Figure 1). The extinction coefficient at $550 \mathrm{~nm}$ decreases from 3.78 to 2.78 upon hydrogenation. The corresponding optical constants are reported elsewhere [11].

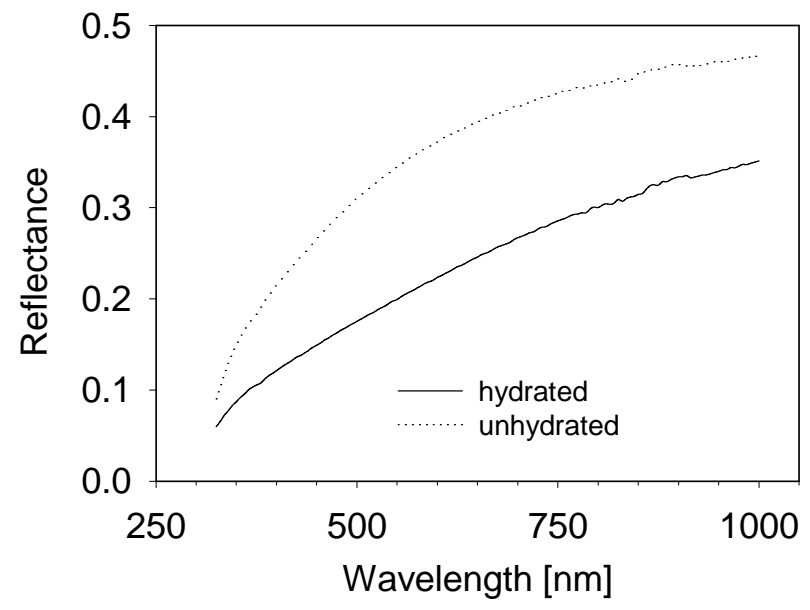

Figure 1. Change in reflectance seen through the substrate of $10 \mathrm{~nm}$ thin Pd on ITO coated glass upon hydration.

Pd coated $\mathrm{Gd}_{\mathrm{x}} \mathrm{Mg}_{1-\mathrm{x}}$ films switch from completely opaque (transmission $<10^{-8}$ ) to visibly transparent (Figure $3 \mathrm{~b}$ ) on exposure to $\mathrm{H}_{2}$. The extremely low transmission of $10^{-6} \%$ was not measured, but calculated from the refractive index data. The complex refractive indices of the gadolinium magnesium alloy in the virgin, hydrided and dehydrided states are shown in Figure 2. The optical constants in the unhydrided state show clearly metallic character with the extinction coefficient rising towards higher wavelengths due to the free electron contribution. The hydrided state shows a dielectric optical response in the visible range. A residual free electron contribution in the hydrided state, as seen in $\mathrm{LaH}_{3}$ [12], was not observed up to $2000 \mathrm{~nm}$. 

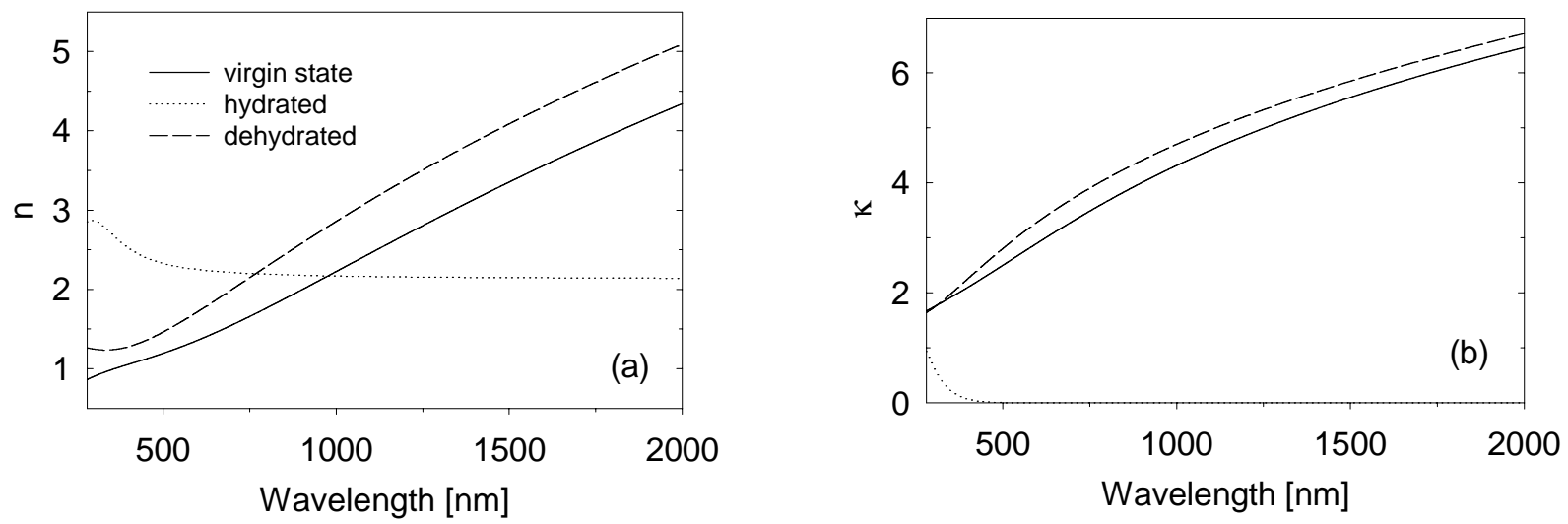

Figure 2. a) Real and b) imaginary part of the refractive index of $\mathrm{Gd}_{0.42} \mathrm{Mg}_{0.58}$ the virgin, hydrided and in the dehydrided state after switching.

The complex refractive index in the reflective state changes significantly from the as-deposited state to the dehydrided state after one cycle and then remains constant during subsequent cycles [11]. Some hydrogen is irreversibly bound in the alloy during the first cycle. For instance in $\mathrm{Gd}_{0.5} \mathrm{Mg}_{0.5}$, hydrogen is retained up to a ratio of $0.8 \mathrm{H} / \mathrm{M}$ [3]. The visible reflectance of the magnesium rich alloy films is lowered from about $65 \%$ to about $60 \%$ by this "formatting" process. The extinction coefficient at $550 \mathrm{~nm}$ in the hydrided state is about $10^{-3}$ for $\mathrm{Gd}_{0.42} \mathrm{Mg}_{0.58}$. Thus it is mainly the Pd cap-layer that limits the visible transparency. The effect of the switching of Pd is estimated to be about 5-8\% visible transmittance for the layer stack. The visible transmission of the approximately $200 \mathrm{~nm}$ thick lanthanide magnesium alloys on a fused silica substrate without the Pd cap-layer lies between 60 and $90 \%$ and is dependent on the spectral position of interference fringes. For maximum visible transparency together with complete opacity in the reflective state a single film of a lanthanide magnesium hydride should be about $240 \mathrm{~nm}$ thick.
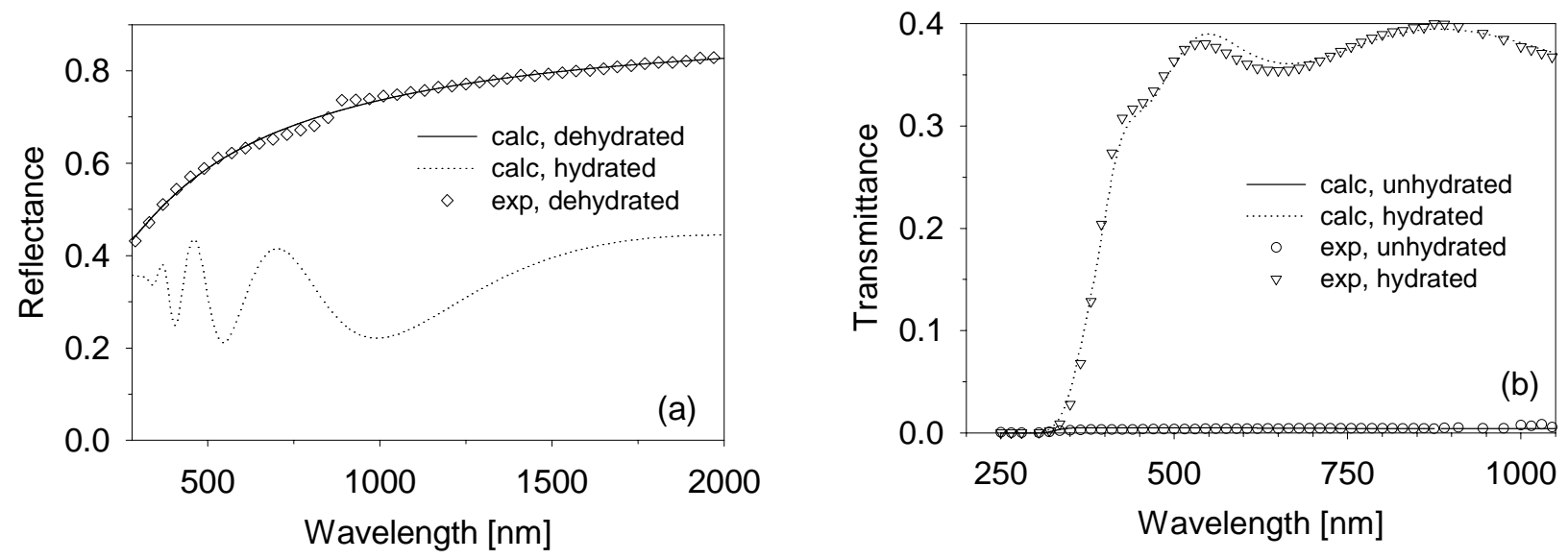

Figure 3. Spectral a) reflectance and b) transmittance of Pd coated $\mathrm{Gd}_{0.42} \mathrm{Mg}_{0.58}$ on silica in reflective, dehydrided and transparent, hydrided state. Symbols depict experimental data, drawn lines correspond to calculated data from the optical constants in Figure 2. 
Figure $3 \mathrm{a}$ shows the calculated reflectance of a $10 \mathrm{~nm}$ Pd coated $\mathrm{Gd}_{0.42} \mathrm{Mg}_{0.58}$ film on silica before and after hydridation together with experimental data for the reflective state. Experimental reflectance of the transparent, hydrided state is not shown, because of the difficulty of properly accounting for the sample holder at near-normal incidence. The excellent fits of calculated data to experimental ellipsometric and transmittance data in the hydrided state, however, support the accuracy of the predicted reflectance for the transparent state. Transmittance behavior of the same sample is shown in Figure 3b. The optical contrast between the transparent hydrided and reflective dehydrided state is extremely high. At $550 \mathrm{~nm}$ it is on the order of $10^{9}$. For comparison the achievable optical contrast with conventional electrochromic tungsten oxide layers (of $400 \mathrm{~nm}$ thickness) is about 8 orders of magnitude lower. The maximum visible transmission, however, is about $80 \%$ for a $\mathrm{WO}_{3}$ film on ITO versus $40 \%$ for Pd- capped magnesium lanthanide hydrides. The hydrogenation reaction rates for the magnesium lanthanide alloy hydrides are much slower than that for Pd. The kinetics of the switching depend on the thickness of the Pd layer, the hydrogen pressure, and the time between deposition and measurement.

\subsection{Electrochemical switching}

Figure 4 shows the initial galvanostatic loading of a samarium film (67nm Sm, 15nm Pd). Two potential plateaus are observed, one at $-690 \mathrm{mV}$ and another one at ca $-820 \mathrm{mV}$, after which the potential drops rapidly before reaching the hydrogen evolution limit. Although the second plateau is less marked than the first one, it is possible to discern a 2/3-1/3 relation in the plateau lengths corresponding to the cubic $\mathrm{SmH}_{2}$ and hexagonal $\mathrm{SmH}_{3}$ stages. During the first potential plateau the transmittance rises up to ca $2 \%$ and then reaches $16 \%$ at the end of the second plateau. The thick palladium layer on this sample limits the maximum transmittance achievable. Once the film has been loaded with hydrogen it can be cycled between the dihydride and the trihydride states.

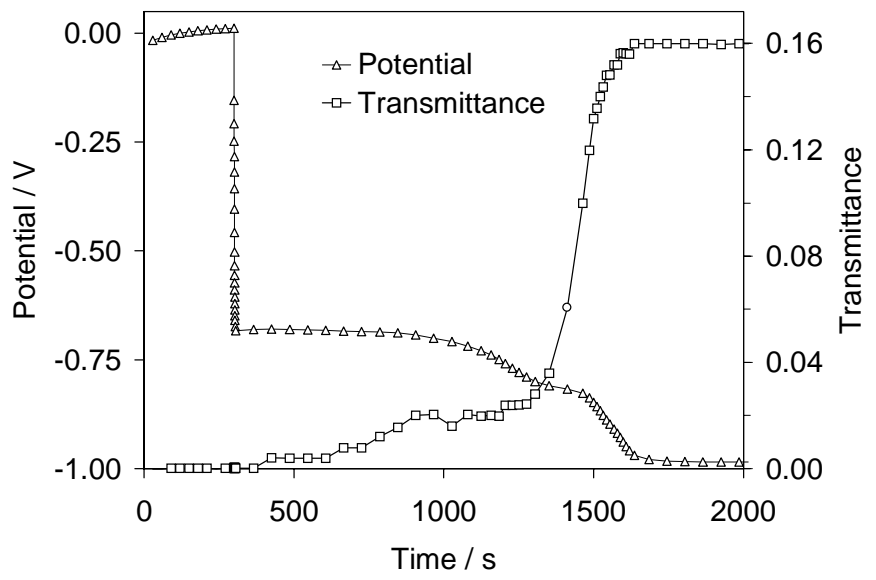

Figure 4. Initial galvanostatic loading in $5 \mathrm{M} \mathrm{NaOH}$ of a $67 \mathrm{~nm}$ thick Sm film capped with15 nm Pd.

Figure 5 shows such cycles at $5 \mathrm{mV} \mathrm{s}^{-1}$ and $10 \mathrm{mV} \mathrm{s}^{-1}$ between $-0.2 \mathrm{~V}$ and $-1.1 \mathrm{~V}$. Two peaks are visible in the cathodic half cycle. Only one is very distinct in the anodic scan. It is, however, 
possible to discern a shoulder just before that peak. It may be that the conversion to $\mathrm{SmH}_{3}$ from $\mathrm{SmH}_{2}$ is a two step process. Figure 6 shows the results of potential step experiments. The sample was held at $-0.2 \mathrm{~V}$ for $60 \mathrm{~s}$ and then $-1.0 \mathrm{~V}$ for $60 \mathrm{~s}$. The first ${ }^{\mathrm{t}}$ step and the $100^{\text {th }}$ step are drawn on the same graph to illustrate the stability of this sample. The response time is ca. $20 \mathrm{~s}$ for the transition from the reflecting to the clear state and less than $10 \mathrm{~s}$ for the reverse transition. These are excellent switching times considering that the Pd layer is very thick, and that the cell geometry was not optimized for this type of measurement.

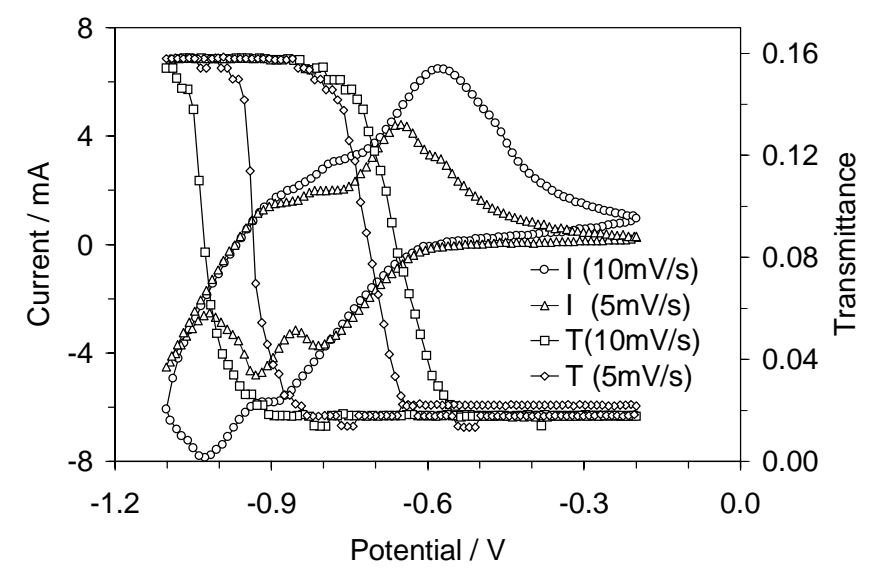

Figure 5. $\mathrm{CV}$ at 5 and $10 \mathrm{mV} \mathrm{s}^{-1}$ in $5 \mathrm{M} \mathrm{NaOH}$ of a $67 \mathrm{~nm}$ thick Sm film capped with $15 \mathrm{~nm}$ Pd.

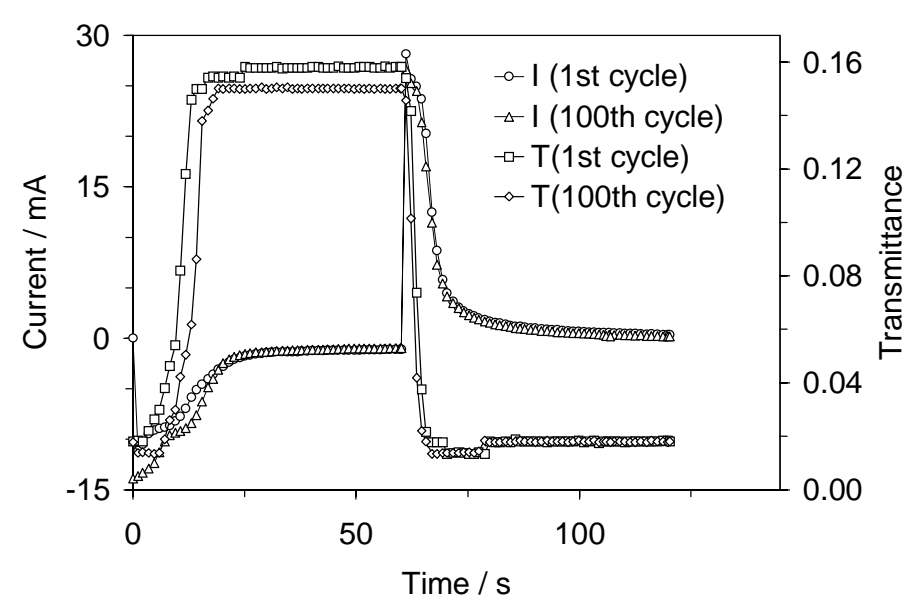

Figure 6. Potential steps in $5 \mathrm{M} \mathrm{NaOH}$ of a $67 \mathrm{~nm}$ thick Sm film capped with $15 \mathrm{~nm}$ Pd. Steps are $-1.0 \mathrm{~V}$ for $60 \mathrm{~s}$ and then $-0.2 \mathrm{~V}$ for $60 \mathrm{~s}$. Cycle \#1 and cycle \#100 are shown.

Figure 7 shows the initial galvanostatic loading of a Gadolinium-Magnesium film (204nm GdMg $+5 \mathrm{~nm}$ Pd). One plateau in potential can easily be identified at $-720 \mathrm{mV}$. After about $500 \mathrm{~s}$ the potential begins to decrease at a nearly constant rate. After 1000s a very sharp transition occurs accompanied by a sudden dramatic in transmittance. The maximum transmittance for this film is 
just below $40 \%$ due to a thinner Pd layer. Figure 9 shows cyclic voltammograms of this sample at 5 and $10 \mathrm{mV} \mathrm{s}^{-1}$. Hydrogen evolution is rapid below $-1.05 \mathrm{~V}$. The anodic half cycle is divided into two waves, one of which does not have a cathodic counter part. This could be the sign of a irreversible oxidation process, but since it is present in all cycles and no sign of degradation is seen, a more plausible explanation is a two step dehydration. Figure 8 presents a potential step experiment on a $204 \mathrm{~nm}$ thick GdMg sample capped with a $5 \mathrm{~nm}$ thick Pd layer. The response time for a change in transmission equal to $90 \%$ of the max span is ca. $10 \mathrm{~s}$ for bleaching and $45 \mathrm{~s}$ for darkening. The transition to the clear state is the same as that of the previous sample even though the film is three times as thick. Transition back to the reflecting state, however takes nearly four times longer, even though the palladium layer is three times thinner. This suggests that the slow process during bleaching takes place on the palladium layer, and that the slow part in the darkening takes place in the GdMg layer.

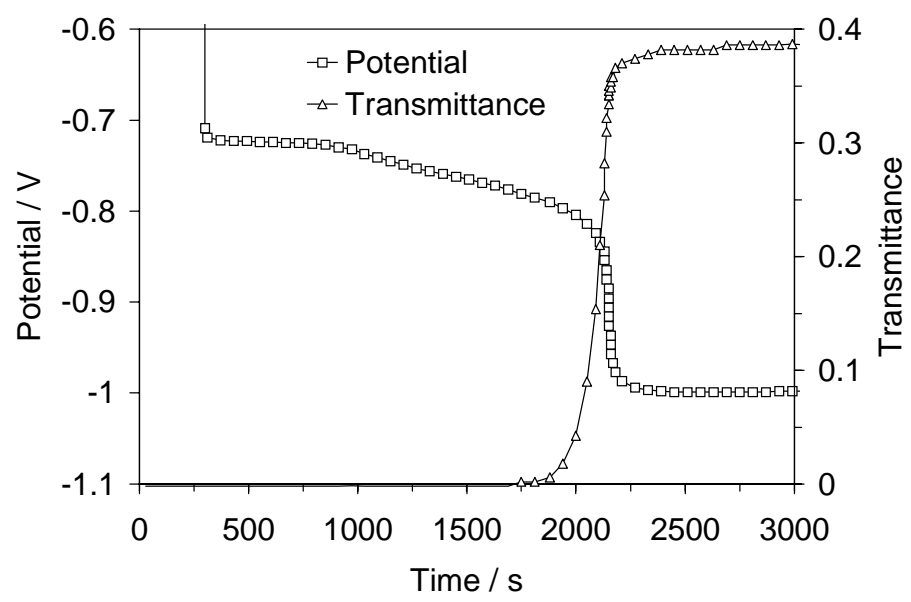

Figure 7. Initial galvanostatic loading in $5 \mathrm{M} \mathrm{NaOH}$ of a $204 \mathrm{~nm}$ thick GdMg film capped with $5 \mathrm{~nm} \mathrm{Pd}$.

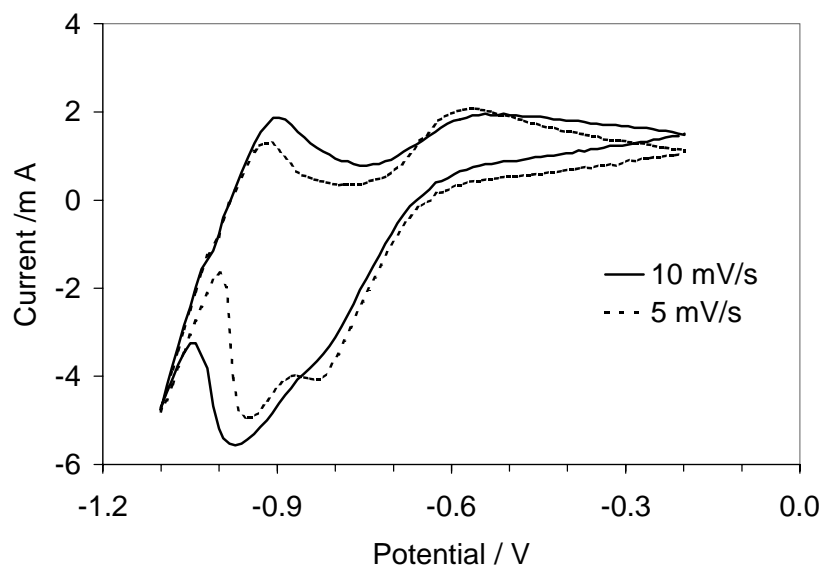

Figure 8. CVs at 5 and $10 \mathrm{mV} \mathrm{s}^{-1}$ in $5 \mathrm{M} \mathrm{NaOH}$ of a $204 \mathrm{~nm}$ thick GdMg film capped with $5 \mathrm{~nm}$ Pd. 


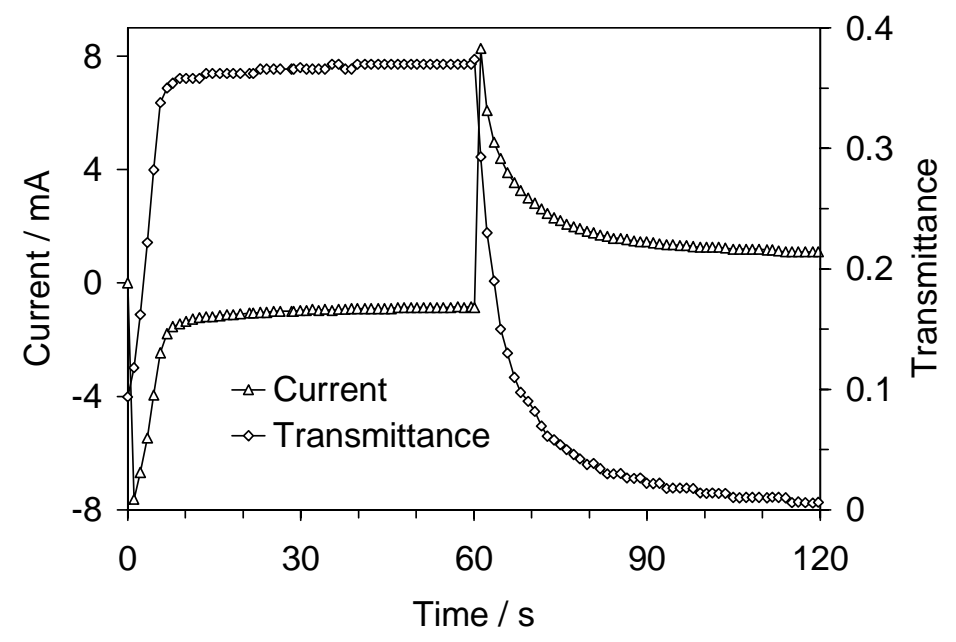

Figure 9. Potential steps in $5 \mathrm{M} \mathrm{NaOH}$ of a $204 \mathrm{~nm}$ thick $\mathrm{GdMg}$ film capped with $5 \mathrm{~nm}$ Pd. Steps are $-1.0 \mathrm{~V}$ for $60 \mathrm{~s}$ and then $-0.2 \mathrm{~V}$ for $60 \mathrm{~s}$. Steps $1-3$ shown.

After 500 potential steps the maximum transmittance is down to around 25\% (Figure 10), while the low transmitting state remains essentially the same. This could indicate a failure of the Pd protecting layer causing oxidation of the GdMg layer. To verify this hypothesis, a sample with the same alloy thickness capped with $15 \mathrm{~nm}$ of palladium was cycled in the same conditions. The results are presented on Figure 11, which show little change in the maximum transmission.

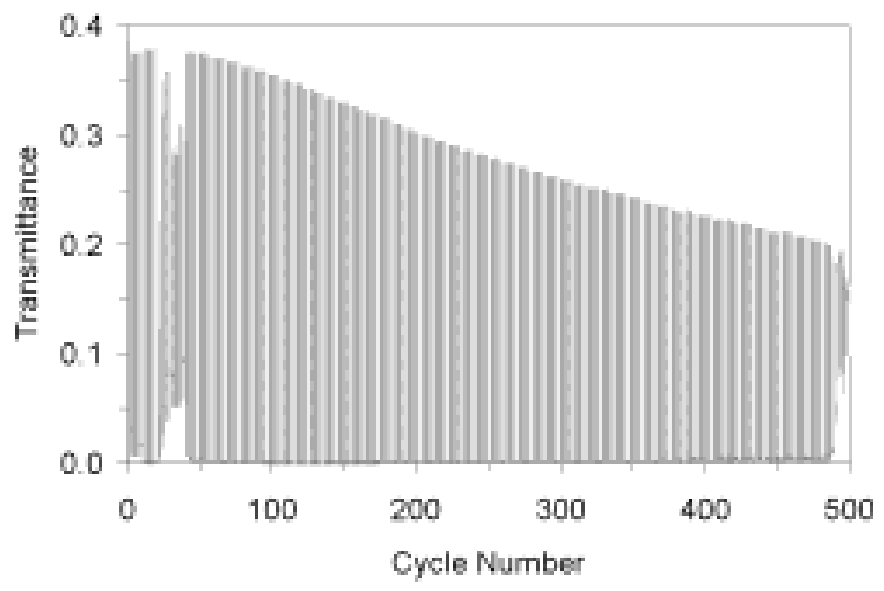

Figure 10. 500 cycles of a $204 \mathrm{~nm}$ thick GdMg film capped with $5 \mathrm{~nm} \mathrm{Pd}$. 


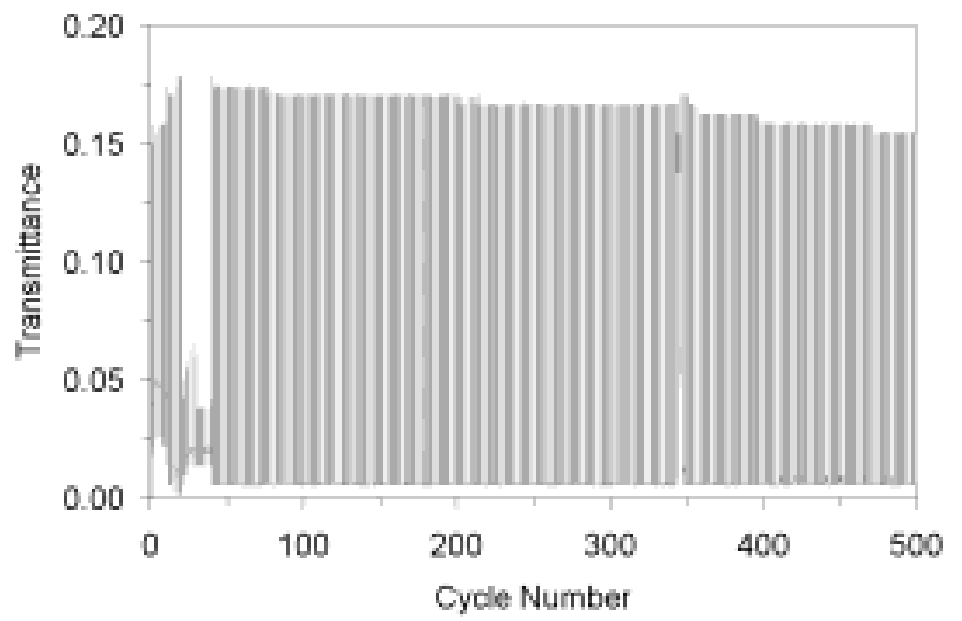

Figure 11. 500 cycles of a $204 \mathrm{~nm}$ thick GdMg film capped with $15 \mathrm{~nm}$ Pd.

\subsection{Energy performance simulations}

The energy performance of these materials was calculated hour-by-hour using the DOE-2 program. We choose the cooling-dominated climate of Phoenix, Arizona and a commercial building module. Details of the simulation can be found in earlier work on conventional electrochromics. [13] Three double-glazed systems were used: First, for comparison, a spectrally selective glazing with a coating having high visible transmittance and low infrared transmittance (due to reflection) combined with an inner clear glazing. The same spectrally selective glazing was used as the inner glazing with both the Gd hydride and the conventional electrochromic based on tungsten oxide (designated M3). The properties of the electrochromics were controlled so as to produce a fixed daylight illuminance at a reference point in the space. Figure 12 shows that both electrochromic types easily outperform the static glazing in terms of cooling energy consumption, especially at high glazing areas. The hydride somewhat outperforms the oxide electrochromic simply because it has a lower transmittance (near zero versus about $8 \%$ ). With this control strategy, the electrochromics are usually found in their darkest states, so the lower level determines the cooling energy savings. The lighting energy consumption is in reverse order with the static glazing performing best and the hydride performing worst, in accordance with their maximum transmittance states. The performance levels, in this case, are much closer together, again because the glazings spend little time in their high transmittance state. Thus, the total energy performance is dominated by the cooling performance and the hydrides perform best. There is little difference between the reflective and absorptive electrochromics, however, because in the double glazed configuration, most of the absorbed energy is transferred outwards. The difference in energy performance that can be achieved between low and very low transmittance levels is then not very great. The near-zero transmittance of the hydride, however, has major implications for cost because it is possible to have privacy at that level and possibly eliminate the expensive shading system. 


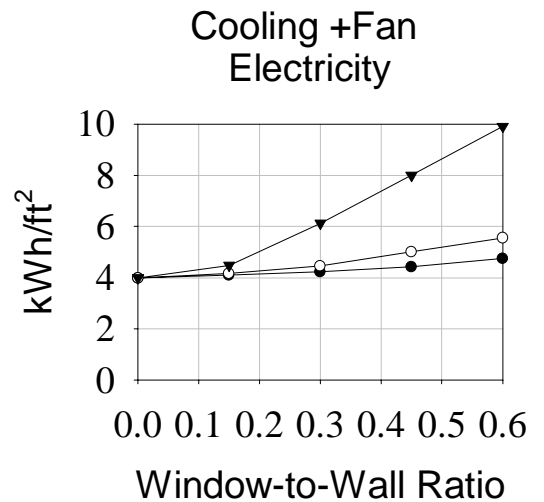

Cooling + Fan + Lighting Electricity

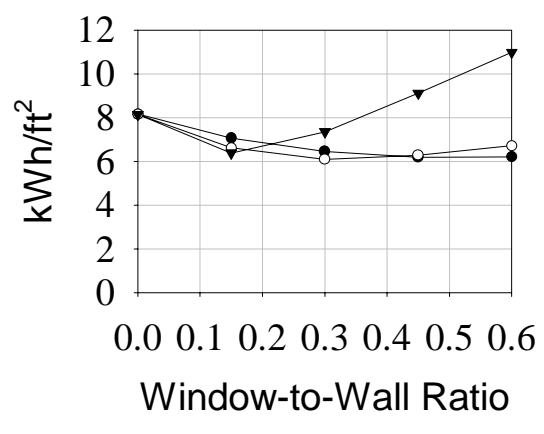

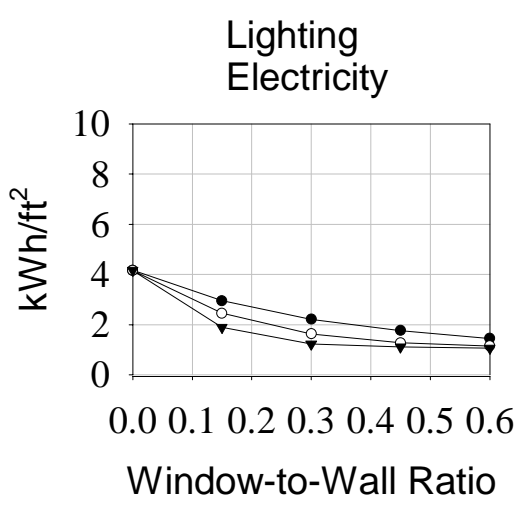

- gd - Spectrally Selective

- M3 - Spectrally Selective

$\rightarrow$ Spectrally Selective - Clear

Figure 12. Comparison of the energy performance of a spectrally selective window, a conventional electrochromic window, and a Gadolinium hydride window. DOE 2.0 simulations.

\section{Conclusion}

Upon hydridation $\mathrm{Gd}_{\mathrm{x}} \mathrm{Mg}_{\mathrm{y}}$ undergoes an optical transition from reflective to transparent. The spectral complex refractive indices were determined in the reflective dehydrided and transparent hydrided phases from 280 to $2000 \mathrm{~nm}$. The optical constants are very different between asdeposited reflective state and the dehydrided reflective state after the first switching. Thin film optical constants of Pd were also measured in the as-deposited and hydrided state. It was found that the optical properties of Pd itself change upon hydration. The response time of $\mathrm{Pd}$ is much shorter than that of the examined magnesium lanthanide hydrides. In the hydrided state the extinction coefficients of the lanthanide magnesium alloys are between $10^{-2}$ and $10^{-4}$ versus 2.78 for hydrided Pd. Therefore, if the protective layer of Pd could be eliminated in (e.g., in a sealed device), a visible transparency of close to $90 \%$ seems to be achievable with $240 \mathrm{~nm}$ thick lanthanide magnesium alloy films. DOE 2.0 calculations have shown that the difference in energy performance that can be achieved between low $\left(\mathrm{WO}_{3}\right)$ and very low (Hydride) transmittance levels is not very great. The near-zero transmittance of the hydride, however, has major implications for cost because it is possible to have privacy at that level and possibly eliminate an expensive shading system. 


\section{Acknowledgment}

This work was supported by the Assistant Secretary for Energy Efficiency and Renewable Energy, Office of Building Technology, State and Community Programs, Office of Building Systems of the U.S. Department of Energy under Contract No. DE-AC03-76SF00098. We gratefully acknowledge Mehri Yazdanian for the DOE2.0 calculations, Paul Laberge for his help with the optical setup and E. Evens for preparation of some of the samples.

\section{References}

1. J.N. Huiberts, R. Griessen, J.H. Rector, R.J. Wijngarden, J.P. Dekker, D.G. de Groot, N.J. Koeman, Nature, 380, 231 (1996).

2. P.H.L. Notten, J. Electrochem. Soc. 143, 3348 (1996).

3. P. van der Sluis, M. Ouwerkerk, P. Duine, Appl. Phys. Lett. 70, 3356 (1997).

4. M. Ouwerkerk, presented at the $11^{\text {th }}$ Int. Meeting on Solid State Ionics, Honolulu, November 1997, to be published in Solid State Ionics

5. W.H. Preuss, B.P. Flannery, S.A. Teukolsky, W.T. Vetterling, in Numerical Recipes, pp523, Cambridge University Press, Cambridge, U.K. (1989).

6. E.D. Palik in Optical Constants of Solids II, Academic Press, New York (1991).

7. P.B. Johnson, R.W. Christy, Phys. Rev. B 9, 5056 (1974).

8. J.H. Weaver, R.L. Benbow, Phys. Rev. B 12, 3509 (1975).

9. A.D. Rakic, A.B. Djurisic, J.M. Elazar, M.L. Majewski, Appl. Optics 37, 5271 (1998).

10. K. von Rottkay, M. Rubin, N. Ozer, Mat. Res. Soc. Symp. Proc. 403, 551 (1996).

11. K. von Rottkay, M. Rubin, P. Duine, submitted to J. Appl. Phys.

12. D.J. Peterman, J.H. Weaver, and D.T. Peterson, Phys. Rev. B 23, 3903 (1981).

13. R. Sullivan, M. Rubin, S. Selkowitz, ASHRAE Trans. 103,.149 (1997) 